\title{
Competências do profissional da informação: uma reflexão a partir da Classificação Brasileira de Ocupações
}

\author{
Sueli Faria \\ Mestre em administração e planejamento de sistemas de informação - \\ PUC-Campinas. Diretora técnica da Biblioteca da Faculdade de \\ Engenharia de Alimentos/Unicamp. \\ E-mail: sulaff@fea.unicamp.br
}

\section{Vanda Fulgêncio de Oliveira}

Bibliotecária responsável pela Biblioteca do Centro de Atenção Integral à Saúde da Mulher (Caism) .

E-mail: vanda@unicamp.br

\section{Liliane Forner}

Diretora técnica da Biblioteca do Instituto de Artes/Unicamp. E-mail: $\underline{\text { liliane@iar.unicamp.br }}$

\section{Floriana D'Astuto}

Bibliotecária de processamento técnico/Biblioteca Central/Unicamp. E-mail: flor $@$ unicamp.br

\section{Resumo}

O trabalho traça um paralelo entre as competências do profissional da informação e as atuais exigências das empresas no contexto da sociedade do conhecimento. A análise foi baseada nas descrições da Classificação Brasileira de Ocupações (CBO) e nas investigações sobre as atuais competências exigidas pelas empresas líderes, bem como em conceitos sobre desdobramentos de competências no contexto da literatura da ciência organizacional. Verificou-se que as competências estabelecidas na CBO para esses profissionais convergem para as competências requeridas nos atuais paradigmas das empresas, com certas limitações. Essas considerações conduziram à sugestão de um mapeamento de competências dos profissionais da informação visando a levantar os pontos críticos, as discrepâncias e excessos, tendo como objetivo estratégias de autogerenciamento da carreira e a definição de políticas públicas condizentes com as tendências atuais.

\section{Palavras-chave}

Competências; Profissional da informação; Classificação Brasileira de Ocupações.

Information professional competencies: a reflection of Brazilian Classification of Occupations

\section{Abstract \\ This paper traces a parallel between the abilities of the Professional of the Information and the current requirements of the companies in context of the Knowledge Society. The analysis was based on the descriptions of the Brazilian Classification of Occupations (CBO) and on the inquiries on the current abilities demanded for the leader companies, beyond concepts on unfoldings of abilities in the context of the organizational science. It was verified that the abilities established in the CBO converge to the abilities required in the current paradigms of the companies, with limitations. These considerations had lead to the suggestion of a mapping of abilities of the professionals of the information aiming auto management of the career, and to the definition of public politics.}

\section{Keywords}

Competencies; Information professional; Brazilian Classification of Occupations.

\section{ESTRATÉGIAS ORGANIZACIONAIS E AS COMPETÊNCIAS HUMANAS}

As organizações estão sendo desafiadas a lidar com ambientes cada vez mais dinâmicos, demandando novas exigências de gestão e novos perfis de lideranças. Grande ênfase tem se dado à questão das competências essenciais da organização, que se referem ao aprendizado coletivo, e das competências do indivíduo. As mudanças não são decorrentes apenas dos avanços tecnológicos, mas também do ambiente que se tornou complexo, demandando transformações permanentes para se garantir a vantagem competitiva.

A sociedade do conhecimento anunciada por autores proeminentes como Peter Drucker, James Quinn, Alvin Tofler, Robert Reich, citados por Nonaka e Takeuchi (1977), distingue-se do passado pelo papel-chave que o conhecimento desempenha nela, em que o trabalhador é o maior ativo para a vantagem competitiva atuando como analista simbólico equipado com conhecimento para identificar, solucionar e avaliar novos problemas. Sveiby $(2000$, p.66) compartilha dessa visão e infere que a aptidão das pessoas que trabalham em equipe, ou as relações que elas mantêm com clientes e fornecedores, são ativos intangíveis. $\mathrm{O}$ autor preconiza a gestão do conhecimento como uma ferramenta que traz benefícios tangíveis, cuja essência é aproveitar os recursos que já existem na empresa para que as pessoas procurem, encontrem e empreguem as melhores práticas, criando um ambiente de aprendizado interativo, no qual as pessoas transfiram o conhecimento, internalizem-no e apliquem-no para criar novos conhecimentos formando a espiral do conhecimento, formulada por Nonaka e Takeuchi (1977).

Albrecht (2004) coloca a inteligência organizacional como modelo para integrar diversos níveis de inteligência individual, de equipe e organizacional, capazes de nutrir a cultura do conhecimento para enfrentar a terceira onda. Programas de treinamentos a fim de trabalhar habilidades como pensamento crítico, criatividade, solução de problemas, tomada de decisões e ultimamente até inteligência emocional são estratégias utilizadas nesse modelo. 
O desenvolvimento do trabalho com o conhecimento em uma organização está diretamente relacionado ao desenvolvimento estratégico de suas competências. Prahalad e Hamel (1990) formulam o core competences como forma de integração do aprendizado coletivo da organização e coordenação das diversas fases de produção e equipes múltiplas de tecnologias. Especialistas das ciências organizacionais enfatizam novas competências organizacionais: flexibilidade, inovação, horizontalidade, criatividade, agilidade, compartilhamento de informação, aprendizagem, gestão do conhecimento, planejamento participativo, empowerment e estratégia competitiva.

Com o deslocamento de ênfase, é crescente o reconhecimento por parte das organizações de que seu capital intelectual deve ser gerido de forma sistemática. Estratégias, mapas do conhecimento e portfólios de iniciativas estão sendo desenvolvidos para capturar e disseminar aquilo que aprendem ao longo do tempo, facilitar o compartilhamento de idéias e experiências, eliminando as barreiras funcionais, impulsionar melhores práticas e gerir seu capital intelectual.

A criação do conhecimento organizacional depende do conhecimento das pessoas, da motivação e da vontade de criar, agir, compartilhar e codificar seu próprio conhecimento individual, enquanto a gestão do conhecimento está em saber o que os colaboradores sabem fazer bem e tirar proveito desse conhecimento com a maior eficiência possível.

\section{O PROFISSIONAL DA INFORMAÇÃO NA SOCIEDADE DO CONHECIMENTO}

O conhecimento vem se tornando diferencial para as organizações que buscam excelência, e sem ele a utilização do potencial humano fica precária, inviabilizando todo o processo de geração de produtos e serviços condizentes com as demandas internas e externas. Independentemente do modelo que elas adotam para a criação do conhecimento organizacional, terão de fazer frente a muitos desafios.

Alguns dos desafios na gestão do conhecimento são enumerados por Gontow (2004), dos quais destacamos os serviços: o alto volume de informações que estão sendo criadas, armazenadas e distribuídas; a incrível velocidade com que o conteúdo do conhecimento está mudando; a necessidade de as organizações serem proativas ao apoiar a criação e a reutilização do conhecimento (...). Contexto este em que o profissional da informação pode inserir-se como ativo e agente criativo, capitalizando sua competência informacional para as estratégias da organização em que atua.
Esse evento pode ser uma oportunidade ímpar de aprendizagem, mas, para aproveitamento dessa mutação, necessário se faz dar maior peso à lógica competência, que é investida da ação do trabalhador rumo a um movimento de ação subjetiva do caráter cada vez mais socializado e interdependente das atividades profissionais.

Os papéis de gerenciamento de informações em uma empresa, segundo McGee e Prusak (1994), cabem funcionalmente a dois grupos de informação: a equipe da biblioteca e a equipe da informática. $\mathrm{O}$ autor afirma que a equipe da biblioteca, especificamente, precisa interagir mais com as demais equipes do grupo de gerenciamento da informação na organização e com as áreas usuárias para analisar se a informação que oferecem tem qualidade, atualidade, precisão, relevância e valor. Já o estudo de caso da KPMG Brasil, realizado por Hommerding e Vergueiro (2004), demonstra a prontidão dos profissionais da informação para atuar em áreas inovadoras como a gestão do conhecimento nas organizações.

Especialistas da informação no Brasil apontam as competências requeridas aos profissionais da informação para essa nova configuração, das quais destacamos: conhecimento interdisciplinar e especializado; capacidade de contextualização; capacidade de conceituação; conhecimento da demanda ou do cliente; domínio de ferramentas e de tecnologias de informação; adaptação ao novo, flexibilidade e abertura às mudanças; capacidade de gerenciamento; lidar com contradições e conflitos; relacionamento interpessoal, excelência na comunicação oral e escrita; lidar com as diversas habilidades funcionais; capacidade de aprendizado próprio e de facilitar o aprendizado dos outros; ser ético, proativo, empreendedor, ter energia, criatividade, consciência coletiva e visualizar o sucesso. (DIAS et alii, 2004; TARAPANOFF et alii, 2004; PESTANA, 2003; FERREIRA, 2003; ARRUDA, 2000).

As competências dos profissionais europeus estão descritas no Guide to Competencies for European Professionals in Library and Information Services e contemplam a adaptabilidade, habilidade analítica, prever ameaças e oportunidades, comunicação, habilidade crítica, mente investigativa, tomada de decisão, saber ouvir, trabalhar em equipe, iniciativa, habilidade organizacional, sensibilidade didática, perseverança, padronização e habilidade de síntese (ASLIB CONSULTANCY PUBLICATIONS, 2004).

A bibliografia norte-americana sobre a questão foca, usualmente, as competências por áreas e campos de 


\section{Sueli Faria / Vanda Fulgêncio de Oliveira / Liliane Forner / Floriana D’Astuto}

atuação de forma distinta. $O$ guia preparado pelo comitê da University of Nebraska-Lincoln University Libraries (AVERY, 2001) estabeleceu um núcleo de competências gerais para atender à compreensão comum das necessidades inerentes a todos os campos de atuação desses profissionais, que se resumem assim: habilidades analíticas/solução de problemas/decisão; habilidades de comunicação; criatividade e inovação; proficiência e conhecimento técnico; flexibilidade/adaptabilidade; habilidade interpessoal; liderança; compreensão organizacional e pensamento global; domínio/ responsabilidade/confiança; habilidade organizacional e de planejamento; administração de recursos; proatividade em relação às necessidades do usuário.

Em linhas gerais, identifica-se uma convergência entre os grupos de competências definidas pelos profissionais europeus e norte-americanos e as apontadas pelos especialistas brasileiros, o que nos leva a crer que os impactos da sociedade do conhecimento tendem a ter as mesmas influências entre os profissionais da informação, independentemente de ser um país desenvolvido ou em desenvolvimento. Resta identificar outras implicações que essas competências propostas e/ou definidas têm causado, e, para tal, estudos diversos vêm, gradativamente, desvendando esses impactos no Brasil.

Neste trabalho, buscamos refletir se as competências definidas para o profissional da informação propiciam uma dimensão nova e rica em oportunidades para que ele aprenda juntamente com as organizações que norteiam o contexto do conhecimento em suas estratégias competitivas.

\section{A LÓGICA COMPETÊNCIA}

Dentre as definições de competência, tomamos por base o documento fruto das Jornadas Internacionales de Deauville, que foca a mudança do comportamento social dos seres humanos em relação ao trabalho e sua organização, que assim a define:

Competência profissional é uma combinação de conhecimentos, de saber-fazer, de experiências e comportamentos que se exerce em um contexto preciso. Ela é constatada quando de sua utilização em situação profissional, a partir da qual é passível de validação. Cabe à empresa identificá-la, avaliá-la, validá-la e fazê-la evoluir (JORNADAS, 1998).

A partir desse conceito, Zarifian (2001), que primeiro na França formalizou e deu um conteúdo científico à noção de competência, preconiza-a alimentada por três "aspectos multidimensionais", quais sejam: 1) a tomada de iniciativa e de responsabilidade do indivíduo; 2) a inteligência prática das situações que se apóia sobre os conhecimentos adquiridos e os transforma; 3 ) a faculdade de mobilizar redes de atores em torno das mesmas situações.

A correlação de competências com base na classificação das ocupações implica diferenciar o conceito sobre sistema de classificação e o de competências. A classificação fornece os elementos de regulação das relações sociais em bases o mais estáveis possível e, conseqüentemente, estabelece um princípio de hierarquia das categorias e dos salários em um dado universo profissional. A competência expressa autonomia de ação do indivíduo em uma equipe ou rede de trabalho, que se engaja subjetiva e voluntariamente, em virtude de suas iniciativas, na melhoria do valor produzido.

Em outras palavras, a classificação das ocupações deve conservar a parte mais estável e duradoura das competências mobilizadas, sem a pretensão de dar conta da parte mais flexível, singular e dinâmica delas. A parte mais estável é constituída pela associação entre os saberes gerais e profissionais que servem de referência a um dado universo profissional e as competências de fundo que permitem, ao mesmo tempo, adquirir e mobilizar ativamente esses saberes, competências que dependem das práticas comunicacionais, da reflexão e da civilidade. Na competência, o que conta é utilização efetiva "sob iniciativa", e toda utilização pressupõe transformação.

\section{O PROFISSIONAL DA INFORMAÇÃO E A CLASSIFICAÇÃO BRASILEIRA DE OCUPAÇÕES (CBO)}

Em 2002 o Ministério do Trabalho e Emprego (MTE) disponibiliza à sociedade a nova Classificação Brasileira de Ocupações (CBO), que vem substituir a anterior, de 1994. Esse documento reconhece, nomeia, codifica os títulos e descreve as características das ocupações do mercado de trabalho brasileiro.

A nova versão contém as ocupações organizadas e descritas por famílias, que constituem um conjunto de ocupações similares correspondente a um domínio de trabalho mais amplo que aquele da ocupação. Uma das novidades foi o método utilizado no processo de descrição, por meio de comitês de profissionais que atuam nas famílias, partindo da premissa de que a melhor descrição é aquela feita por quem exerce efetivamente cada ocupação.

Essa premissa, no entanto, deve ser analisada com cautela, como aponta a coordenadora da pesquisa da CBO 2002 
nas áreas das Ciências e das Artes - Liliana Segnini, em entrevista para o Jornal da Unicamp: "A participação dos trabalhadores e profissionais ativos no mercado descrevendo o que fazem em seus respectivos trabalhos informa o quanto o desemprego possibilita acúmulo de atividades e intensificação do trabalho para aqueles que permanecem empregados. Sua declaração deixa claro um padrão de competências idealizado para os trabalhadores na $\mathrm{CBO}$ : "O contexto de desemprego fornece espaço político para exigir que o trabalhador faça mais do que fazia para permanecer no emprego (...) estamos diante de descrições freqüentemente apontadas, pelos próprios participantes, como superestimadas" (SUGIMOTO, 2004, p.3).

De acordo com MTE, a CBO tem uma dimensão estratégica importante, na medida em que, com a padronização de códigos e descrições, poderá ser utilizada pelos mais diversos atores sociais do mercado de trabalho. Terá relevância também para a integração das políticas públicas do MTE, sobretudo no que concerne aos programas de qualificação profissional e intermediação da mão-de-obra, bem como no controle de sua implementação.

Os profissionais da informação estão codificados na CBO (2003) sob número 2612, formando uma família que compõe:

- 2612-05 - Bibliotecário, Bibliógrafo, Biblioteconomista, Cientista da informação, Consultor de informação, Especialista de informação, Gerente de informação, Gestor de informação.

- 2612-10 - Documentalista - Analista de documentação, Especialista de documentação, Gerente de documentação, Supervisor de controle de processos documentais, Supervisor de controle documental, Técnico de documentação, Técnico em suporte de documentação.

- 2612-15 - Analista de informações - Pesquisador de informações de rede.

Vale lembrar que não existe consenso em relação ao conceito de profissional da informação - mas uma variedade de denominações para os grupos que compõem este segmento - e também em relação às famílias e suas atribuições:

Seja-nos permitido expressar nosso assombro ante o descompasso observado entre a definição das tarefas ocupacionais, eminentemente práticas e rotineiras tanto dos agora denominados profissionais da informação como dos arquivistas e museólogos seriam estes excluídos pelo Ministério do Trabalho e do Emprego do grupo dos profissionais da informação? - e os estudiosos da ciência da informação, no mundo inteiro, os quais consideram a informação como entidade central no processo de desenvolvimento das sociedades, na sua marcha para o futuro (ROBREDO, 2003, p. 162).

O autor acrescenta ainda que os perfis apresentados para os profissionais da informação não condizem com as necessidades e anseios das comunidades de usuários, cada vez mais exigentes:

Na nossa opinião, a interdisciplinariedade e a multidisciplinariedade e sobretudo o rigor científico da pesquisa em ciência da informação (...) apontam também para a multidisciplinariedade da participação de profissionais de origens e formações diversificadas. É impossível pensar num tipo único de profissional da informação com conhecimento universal (...) e mais impossível ainda pensar que esses perfis ocupacionais apresentados pelo Ministério correspondem, de alguma forma, aos perfis que, na realidade, a sociedade está a exigir dos verdadeiros profissionais da informação (ROBREDO, 2003, p. 162-163).

A despeito dos riscos e limitações do instrumento, utilizamos a $\mathrm{CBO}$ como parâmetro para análise das competências requeridas para o universo da informação, por ter sido formulada a partir da descrição dos próprios profissionais e também por estar sendo utilizada pelas empresas e instituições como ferramenta de pesquisa para formulações de planos de cargos e salários.

Buscamos, assim, verificar o grau de equivalência entre as competências $\mathrm{CBO}$ e as competências essenciais apontadas pelas empresas dos diversos segmentos (serviços, indústria, comércio varejista, atacadista, telefonia, autarquia, instituição financeira), tomando por base a investigação de Gramigna (2002), que resultou em cerca de 100 indicadores de desempenho, que, categorizados, tornaram-se passíveis de observação direta e mensuração no período de 1997 a 2000.

As tentativas de montar escores de competências remontam de algum tempo em que despontam Claude Levy Leboyer, Bouyegues, Dulewicz, McCauley, entre outros citados em Gramigna (2002). Na investigação referida, as competências mais valorizadas pelas empresas para o seu desenvolvimento organizacional constituíram o rol de 15 competências que utilizamos para análise, complementada pelo desdobramento das mesmas para 
elucidação de todos os aspectos inerentes a cada competência.

A metodologia de desdobramento de competências desenvolvida no estudo de Gramigna valeu-se da metáfora "árvore das competências", cujos três componentes raízes, tronco e copa, combinados, formam um todo. O desenvolvimento de competências do ser humano pode ser comparado ao processo de crescimento da árvore: a raiz representa as atitudes e valores, o tronco corresponde ao conhecimento e a copa às habilidades. As competências que compõem o sistema são conceituadas e desdobradas conforme exemplo esboçado na tabela 1 .

O propósito desse paralelo foi desvendar se as competências estabelecidas para o profissional da informação afluem para as preconizações das estratégias organizacionais diante dos desafios da gestão do conhecimento.

A tabela 2 apresenta as competências pessoais do profissional da informação descritas na Classificação Brasileira de Ocupações e as competências correspondentes ou correlatas que fazem parte do rol das competências requeridas pelas organizações.

À luz das competências exigidas pelas organizações e do desdobramento de competências requeridas pelas organizações, verificou-se que:

a) a competência "manter-se atualizado" pode ser equiparada à competência "disposição para mudanças", que é a capacidade de gerar alternativas para o trabalho, alternando rotinas para adequálas às necessidades. Trata-se da capacidade de inovar e propor mudanças em suas estratégias de atuação, em que atualização é um pré-requisito;

b) a competência "trabalhar em equipe e em rede" é correlata à competência "afetividade", que é a capacidade de estabelecer compromissos com abertura e transparência, criando vínculos que favorecem a atuação em equipes e o com-
TABELA 1

Exemplo de desdobramento de competência

\begin{tabular}{|c|c|c|c|}
\hline Conceito & \multicolumn{3}{|c|}{ Desdobramento } \\
\hline Comunicação & Atitudes & Conhecimentos & Habilidades \\
\hline $\begin{array}{l}\text { Capacidade de } \\
\text { expressar-se de forma } \\
\text { clara, precisa e } \\
\text { objetiva, bem como } \\
\text { habilidade para ouvir, } \\
\text { processar e } \\
\text { compreender o } \\
\text { contexto da } \\
\text { mensagem, } \\
\text { argumentar com } \\
\text { coerência, usando } \\
\text { feedback de forma } \\
\text { adequada e } \\
\text { facilitando a } \\
\text { interação entre as } \\
\text { partes. }\end{array}$ & $\begin{array}{l}\text { - Faz anotações enquanto } \\
\text { ouve. } \\
\text { - Mantém seu grupo } \\
\text { atualizado, informando } \\
\text { fatos novos. } \\
\text { - Demonstra atenção aos } \\
\text { outros em sua postura } \\
\text { corporal. } \\
\text { - Busca informações e } \\
\text { pergunta quando tem } \\
\text { dúvida. } \\
\text { - Esclarece seus pontos de } \\
\text { vista. } \\
\text { - Reage de forma natural } \\
\text { aos feedbacks com críticas. } \\
\text { - Oferece feedback com } \\
\text { propriedade. }\end{array}$ & $\begin{array}{l}\text { - processo de } \\
\text { comunicação. } \\
\text {-língua portuguesa }\end{array}$ & $\begin{array}{l}\text { É capaz de se } \\
\text { comunicar com } \\
\text { argumentos, fatos e } \\
\text { dados coerentes. } \\
\text { - Apresenta a } \\
\text { comunicação falada, } \\
\text { escrita ou gráfica de } \\
\text { forma organizada. } \\
\text { - Estabelece contatos } \\
\text { com facilidade. } \\
\text { - Quando se comunica, } \\
\text { os outros entendem. } \\
\text { - Interpreta a } \\
\text { comunicação com } \\
\text { propriedade. } \\
\text { - Apresenta relatórios } \\
\text { conclusivos. }\end{array}$ \\
\hline
\end{tabular}

TABELA 2

Competências do profissional da informação e suas correspondências no núcleo de competências exigidas pelas organizações

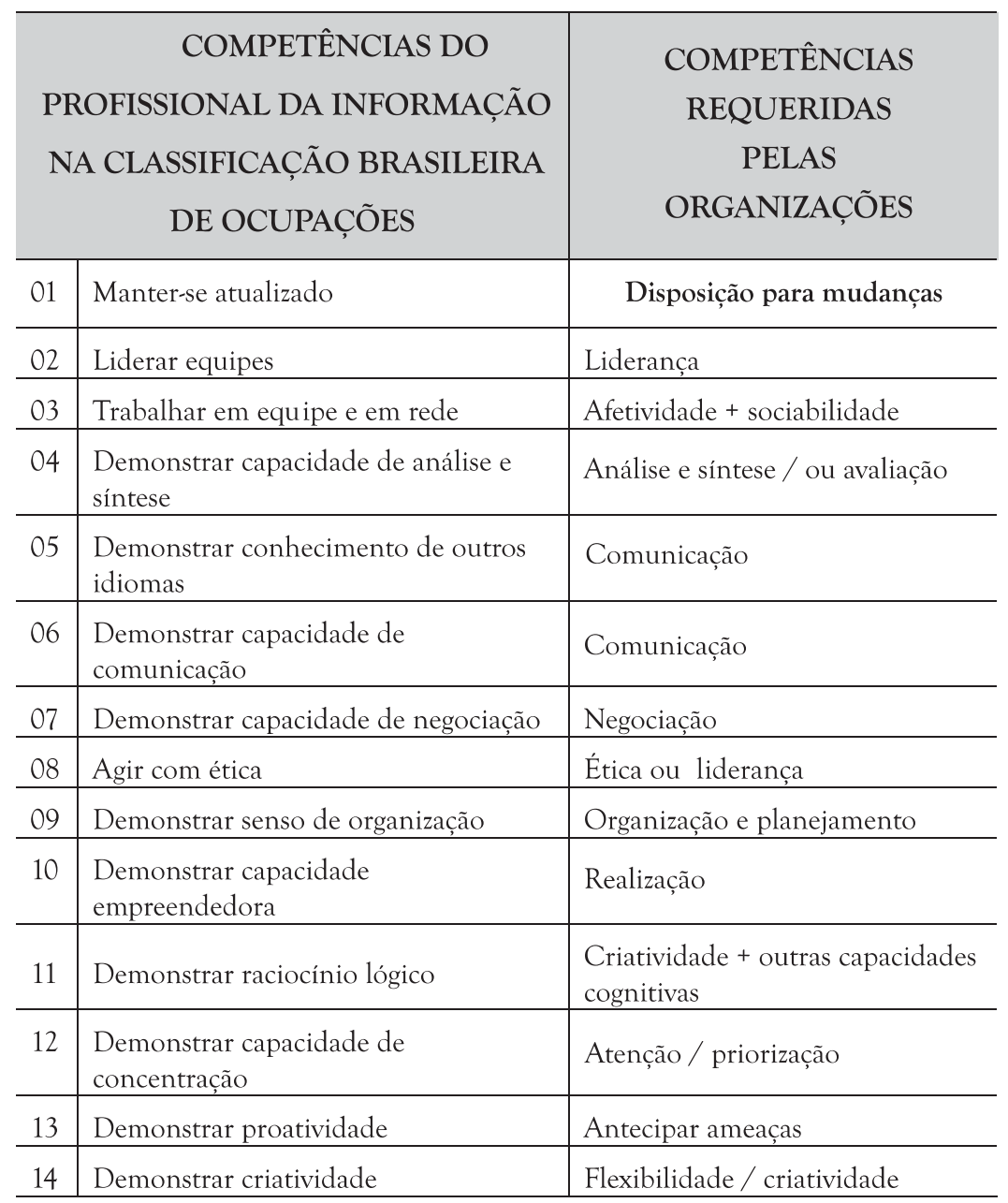


partilhamento de estratégias e interesses. Define a qualidade dos compromissos que as pessoas estabelecem e a "sociabilidade", que é a capacidade de adaptar-se ao contexto e de ampliar sua rede de relacionamento;

c) a competência "conhecimento de idiomas" é considerada um desdobramento da competência "comunicação" - que é a capacidade de expressar-se de forma clara, precisa e objetiva, bem como habilidade para ouvir, processar e compreender o contexto da mensagem, argumentar com coerência, usando feedback de forma adequada e facilitando a interação entre as partes;

d) a competência "ética" é apontada como um desdobramento da competência "liderança" em algumas empresas e isolada em outras;

e) a competência "capacidade empreendedora" pode ser equiparada à competência "realização" que traduz a disposição aos desafios e capacidade de se automotivar diante das situações ainda não experimentadas. Mostra o grau de motivação com que o profissional se envolve nas diversas situações de trabalho e sua ambição para crescer;

f) a competência "raciocínio lógico" não tem sido empregada no núcleo de competências das empresas investigadas. Arriscamos aqui a considerar que a indissociabilidade entre o consciente racional e as atividades criativas leva as organizações a nomear a criatividade para representar as competências cognitivas;

g) a competência "demonstrar capacidade de concentração" pode ser equiparada à competência "atenção/priorização", que revela a visão global e percepção do contexto, capacidade de finalização e forma com que define prioridades em seu trabalho. Revela a capacidade de atender a demandas externas, refazendo sua programação de trabalho;

h) a competência "demonstrar proatividade" tem equivalência com a competência "antecipar ameaças", que revela a capacidade para antecipar ameaças e oportunidades e promover ações estratégicas.

Verificou-se, na análise, que $43 \%$ dos itens estabelecidos na $\mathrm{CBO}$ compõem o núcleo de competências das organizações, e $57 \%$ dos itens são competências correlatas. De acordo com o estudo que fundamentou a análise, três competências - comunicação, liderança e criatividade - são apresentadas repetidas vezes na CBO sob denominações diferentes. Elas, entretanto, têm o mesmo valor e força que as outras.

Ci. Inf., Brasília, v. 34, n. 2, p. 26-33, maio/ago. 2005
Uma questão que levantamos, na ótica da literatura organizacional, é que o conjunto de competências dos profissionais da informação não contempla alguns aspectos que compõem as exigências atuais das organizações, dentro de um conceito progressivo, como, por exemplo, a inteligência emocional. Essa característica pode ser valiosa e complementar à competência de trabalhar em equipe e em rede, pois, para tal, o profissional deve saber elevar sua inteligência emocional para estar apto a articular-se em grupos.

Podemos observar, todavia, que as competências regulamentadas para o profissional da informação estão inseridas no rol de competências requeridas pelas empresas líderes para quaisquer funções, apontando para uma ampliação da envergadura da competência exigida para esse profissional, pois a síntese das diferentes competências que podem ser mobilizadas para um conjunto de atividades eleva o campo de sua responsabilidade, o que lhe permite maior orientação.

Podemos inferir que as competências da $\mathrm{CBO}$, embora não tão abrangentes, alimentam a definição multidimensional de competência de Zarifian (2001), envolvendo facetas que vão do individual ao sociocultural, situacional e processual, tornando o trabalho mais reflexivo, e se transforma em linguagem com ligação entre as competências técnicas e comunicativas.

\section{CONSIDERAÇÕES FINAIS}

No debate entre os especialistas da área da informação, há ênfase na idéia de que o domínio de determinadas competências leva os profissionais e as organizações que os empregam a fazer a diferença no mercado.

Diante das transformações nas estratégias organizacionais decorrentes dos processos de globalização e convergências dos meios de comunicação, o principal input dos trabalhadores passou a ser a capacidade de criar, aprender e desenvolver novos conceitos, produtos e serviços baseados estritamente no conhecimento. O imperativo de se inserir nessa dinâmica induz o profissional da informação a buscar o alinhamento de suas competências e seus respectivos desempenhos aos paradigmas em pauta. Desenvolver esse tipo de recurso, fazendo dele a base de uma estratégia competitiva, assegura seu crescimento futuro.

O compartilhamento de novas idéias e experiências para superação de barreiras funcionais e organizacionais se dá mediante a gestão de pessoas. E esta pressupõe a gestão das competências, cujo mapeamento surge como uma ferramenta para facilitar o gerenciamento das 


\section{Sueli Faria / Vanda Fulgêncio de Oliveira / Liliane Forner / Floriana D'Astuto}

competências individuais e institucionais, dando ênfase às capacidades tácitas.

Com o deslocamento de ênfase no mercado de trabalho da sociedade do conhecimento e o conseqüente desafio aos perfis emergentes, o mapeamento de competências tem sido uma ferramenta estratégica nas práticas das organizações para a prospecção de suas competências. Por meio do mapeamento, é possível levantar os pontos fortes, que tornam as pessoas aptas para algumas tarefas, e os pontos fracos, que devem ser aperfeiçoados para que o profissional possa autogerenciar sua carreira e investir no desenvolvimento daquelas consideradas importantes para o campo no qual pretende atuar.

$\bigcirc$ processo de mapeamento deve prescindir de uma estrutura tal que propicie ações futuras como a criação de um banco de competências e de um centro de carreiras, que abrange a gestão por competências alinhado , gestão das ações de desenvolvimento, coaching para professores, colégio de mentores, sistema de gestão integrado para carreiras, banco de oportunidades, produtos e serviços para carreiras (PINHEIRO, 2004).

De modo sintético, o planejamento e gestão do projeto resume-se em algumas etapas que compreendem sensibilização das pessoas, pesquisa de perfil e de valores, modelo de competências, ferramentas de armazenagem/ busca, aplicação e processamento, devolutivas, avaliação e continuidade.
Os modelos de mapeamento são estruturados a partir das competências essenciais previamente levantadas e definidas - que é uma pesquisa de valores organizacionais e profissionais aplicados em amostragens que relacionem os diversos perfis de profissionais da informação com atuação em áreas diversificadas da sociedade, que gerarão os desdobramentos que nada mais são do que a ampliação do domínio de cada competência. A definição do núcleo de competências deve ser estruturada com base nas competências relacionadas como fatores críticos de sucesso em cada unidade de negócios ou grupo de funções. A construção do modelo estratégico e sua mensuração demandam uma expertise em psicologia e correlação com funções organizacionais.

A exemplo das organizações e de certos grupos de funções, podemos considerar a possibilidade de um mapeamento de competências dos profissionais da informação em âmbito regional ou institucional, para a construção de bancos de indicadores de competência, objetivando o desenvolvimento de competências para os diversos grupos de funções que a área da informação agrega.

Esses indicadores visíveis e compartilhados viriam servir de subsídio à formulação de estudos prospectivos, para identificação de prioridades para investimentos que remetam a uma ação que vise à aprendizagem da categoria sobre si mesma e, conseqüentemente, à definição de políticas públicas condizentes com as tendências atuais.

Artigo recebido em 16/06/2005 e aceito para publicação em 05/01/2006. 


\section{Competências do profissional da informação: uma reflexão a partir da Classificação Brasileira de Ocupações}

\section{REFERENCIAS}

ALBRECHT, Karl. Um modelo de inteligência organizacional. HSM Management, São Paulo, v. 3, n. 44, p. 30-34, maio/jun. 2004.

ARRUDA, Maria da Conceição Calmon et al. Educação, trabalho e o delineamento de novos perfis profissionais: o bibliotecário em questão. Ciência da Informação, Brasília, v. 29, n. 3, p. 14-24, set./dez. 2000.

ASSOCIATION FOR INFORMATION MANAGEMENT. Consultancy publications: the guide to competencies for European professionals in library and information services. Disponível em: $<\underline{\text { http: }}$ /www.aslib.co.uk/pubs/2001/18/01/aptitudes.htm>. Acesso em: 02 jun. 2004

AVERY, Elizabeth Fuseler; DAHLIN, Terry (Ed.). Staff development: a practical guide, 3. ed. Chicago: ALA Editions, 2001. Disponível em:

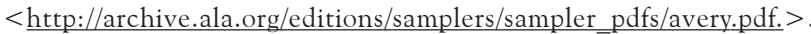
Acesso em: 26 jan. 2006.

BRASIL. Ministério do Trabalho. Classificação brasileira de ocupações. Brasília, 2002. Disponível em: < http://www.mtecbo.gov.br/index.htm >. Acesso em: 30 maio 2004

DIAS, Maria Matilde Kronka et al. Capacitação do bibliotecário como mediador do aprendizado no uso de fontes de informação. Revista Digital de Biblioteconomia e Ciência da Informação, Campinas, v. 2, n. 1, p. 1-16, jul./dez. 2004. Disponível em: <http://www.unicamp.br/bc $>$. Acesso em: 26 jan. 2006.

FERREIRA, Danielle Thiago. Profissional da informação: perfil de habilidades demandadas pelo mercado de trabalho. Ciência da Informação, Brasília, v. 32, n. 1, p. 42-49, jan./abr. 2003.

GONTOW, Rejane. A gestão do conhecimento e os processos de inovação nas organizações. Ribeirão Preto: UNAERP, 2004. Disponível em: < http:/ /www.unaerp.br/biblioteca/diadobibli.ppt>. Acesso em: 16 jun. 2004

GRAMIGNA, Maria Rita. Modelo de competências e gestão dos talentos. São Paulo: Makron Books, 2002. 161 p.
HOMMERDING, Nadia M. D.; VERGUEIRO, Waldomiro. Profissionais da informação e o mapeamento do conhecimento nas organizações: o caso da KPMG Brasil. Revista Digital de Biblioteconomia e Ciência da Informação, Campinas, v. 2, n. 1, p. 17-36, jul./dez. 2004. Disponível em: <http://www.unicamp.br/bc >. Acesso em: 26 jan. 2006.

MARCIAL, Elaine. O papel do profissional da informação no trabalho de inteligência competitiva. Brasília: ABRAIC, 2003. Disponível em: < http:/ Lwww.abraic.org.br>. Acesso em: 02 jun. 2004.

MCGEE, James; PRUSAK, Laurence. Gerenciamento estratégico da informação. Rio de Janeiro: Campus, 1994.

NONAKA, Ikujiro; TAKEUCHI, Hirotaka. Criação de conhecimento na empresa. 8. ed. Rio de Janeiro: Campus, 1977.

PESTANA, Maria Cláudia et al. Desafios da sociedade do conhecimento e gestão de pessoas em sistemas de informação. Ciência da Informação, Brasília, v. 32, n. 2, p. 77-84, maio/ago. 2003.

PINHEIRO, Eduardo. Projeto MAPCOM: mapeamento de competências dos engenheiros politécnicos da USP. São Paulo: Associação dos Engenheiros Politécnicos, 2004.

PRAHALAD, C. K.; HAMEL, G. The core competence of the corporation. Harvard Business Review, v. 68, n. 3, p. 79-93, 1990.

ROBREDO, Jaime. Da ciência da informação revisitada aos sistemas humanos de informação. Brasília: Tesaurus, 2003.

SUGIMOTO, Luiz. O ofício de cada um. Jornal da Unicamp, Campinas, n. 256, jun. 2004.

SVEIBY, Karl E. O valor do intangível. HSM Management, São Paulo, v. 4, n. 22, p. 66-69, set./out. 2000.

TARAPANOFF, Kira; SUAIDEN, Emir; OLIVEIRA, Cecília Leite. Funções sociais e oportunidades para profissionais da informação. DataGramaZero: revista de ciência da informação, v. 3, n. 5, out. 2002.

ZARIFIAN, Philippe. Objetivo competências: por uma nova lógica. Tradução de Maria Helena C. V. Trylinski. São Paulo: Atlas, 2001. 